\title{
Mini Dental Implants as a Simple Treatment Alternative for Edentulous Mandibular Cases
}

\author{
${ }^{1} \mathrm{PC}$ Jacob, ${ }^{2}$ Nitesh Rai, ${ }^{3}$ Digvijaya P Patil \\ ${ }^{1}$ Professor, Department of Prosthodontics, Krishnadevaraya College of Dental Sciences, Bengaluru, Karnataka, India \\ ${ }^{2}$ Associate Professor, Department of Prosthodontics, Krishnadevaraya College of Dental Sciences, Bengaluru, Karnataka, India \\ ${ }^{3}$ Postgraduate Student, Department of Prosthodontics, Krishnadevaraya College of Dental Sciences, Bengaluru, Karnataka, India
}

Correspondence: PC Jacob, Ora-Care Dental Clinic, 101, Maria Plaza, 81 Coles Rd, Frazer Town, Bengaluru-560005, Karnataka India, e-mail: pcjacob66@gmail.com

\section{ABSTRACT}

Path-breaking treatment plans for edentulous patients have been theorized by researchers. Implant retained overdentures using mini dental implants are a simple treatment alternative to the problem of an unstable mandibular complete denture and a long, traumatic and expensive treatment plan of conventional implant-supported prostheses. This paper reports on two patients, who have been successfully rehabilitated with implant-retained overdentures using mini dental implants (3M Imtec). The methodology of treatment has also been explained.

Keywords: Implant-retained overdenture, Edentulous patient, Mini dental implant, Procedure, Immediate loading, Clinical success.

\section{INTRODUCTION}

Implant-retained prosthesis is defined as any prosthesis that is completely or partly supported by an implant or implants. ${ }^{1}$ Dental implants have been used for many years in the rehabilitation of edentulous patients and have proven long term success. ${ }^{2,3}$ Studies have shown up to $95 \%$ overall satisfaction and improvement from the patients perspective. ${ }^{10}$ Patients were satisfied with appearance, function and comfort of their dentures and the outcome of the treatment. ${ }^{4,5}$

Conventional dental implants have proven to be a longterm clinical success in implant-supported overdentures. ${ }^{6,13}$ However, anatomic limitations, bony morphology of elderly and physically debilitated patients, greater burden of maintenance care, longer duration of treatment and inadequate funds make mini dental implants a more acceptable alternative. $^{7}$

Mini dental implants (MDI) are ultrasmall, biocompatible titanium alloy implant screws. They are miniature with diameters from 1.8 to $2.4 \mathrm{~mm}^{8}$ (standard thread design that act like the root of a tooth, a retaining fixture with an o-ring is incorporated into the patient's denture) and length varies from 10 to $18 \mathrm{~mm}$.

This minimally invasive technique is fast becoming the system of choice for stabilizing the prostheses of denture patients. ${ }^{11}$ The omission of peri-implant surgery, together with simple integration of implants into complete dentures, minimizes the duration of treatment and makes it more affordable. MDI's have smaller surface than conventional implants, the load transferred to the bone-implant interface by a horizontal force is greater than conventional implants. ${ }^{9}$
As bite force decreases from posterior to anterior, placing the implant in anterior area of denture may compensate for potential pressure peaks. There is lack of studies on clinical outcomes of mini dental implants, but some suggest that the implant survival of reduced diameter implants was identical to the survival of conventional implants. ${ }^{10}$

\section{PROCEDURE}

\section{Preoperative Planning}

After patient selection (Fig. 1), an orthopantomogram (OPG) (Fig. 5) and lateral cephalogram were taken. Radiographic evaluation of surgical site in terms of bone volume, density and height was done. Appropriate implant sites, the number of implants, their length and angulations were decided. The implants should be placed approximately 5 to

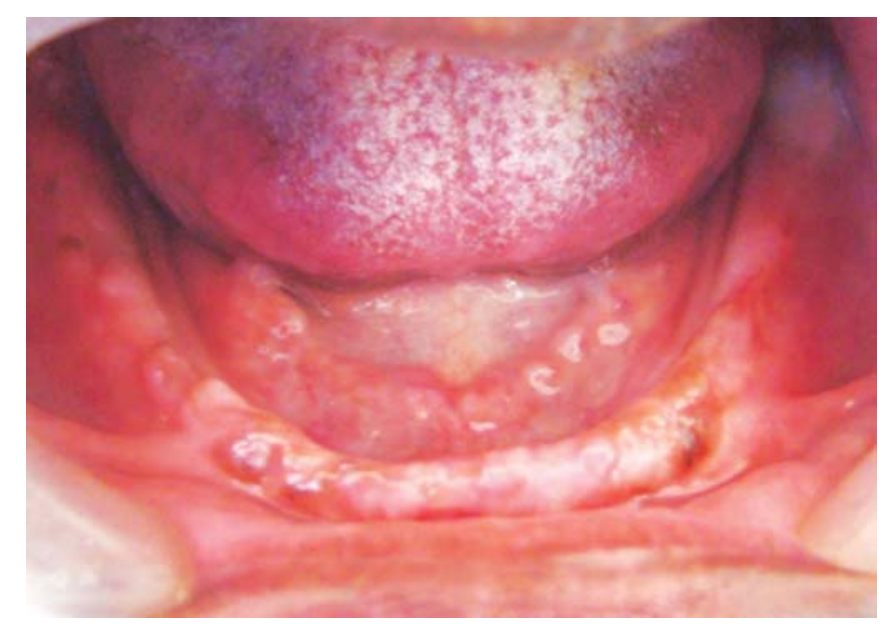

Fig. 1: Edentulous mandible 
$8 \mathrm{~mm}$ apart from each other and at the beginning at least $7 \mathrm{~mm}$ anterior to the mental foramen. The patient's lower denture is then fabricated or modified, followed by identification of appropriate implant sites.

\section{Surgical Protocol}

Following application of local anesthesia, entry points for each implant are marked on the patient's tissue via bleeding points or a marker. The pilot drill $(1.1 \mathrm{~mm})$ is delicately placed over the entry point and lightly pumped up and down until the cortical plate is penetrated. No incision is necessary. The average depth is one-third to one-half the threaded length of the implant. Sterile irrigation is utilized throughout the drilling procedure. In extremely dense bone, an extended penetration may be required. The pilot hole depth should never equal the length of the implant, as the tip of the drill is wider than the tip of the implant.

Implant insertion is done into the pilot opening using the finger driver, rotating clockwise, while exerting downward pressure. This procedure initiates the self-tapping process and is used until noticeable bony resistance is encountered. Then, the winged thumb wrench is used to thread the implant into place until the wrench becomes difficult to turn. In final stage, small, incremental, carefully controlled ratchet turns are done for final seating. In the very dense bone (type I density), the implants were unscrewed and rescrewed to a final position. ${ }^{12}$ This selfadvancing step is repeated several times to prevent mini dental implants from fracture in the very dense bone (Figs 2 and 7).

The ideal length allows the abutment head to protrude from the gingival soft tissue at its full length but with no neck or thread portions visible. Torque should not exceed $50 \mathrm{Ncm}$ during implant placement. Immediate loading of implants is done only when at least 30 to $35 \mathrm{Ncm}$ of resistance is met upon insertion.

\section{Prosthetic Protocol}

Tissue surface of denture is relieved to accommodate implants and metal housings. Blockout shims are trimmed to appropriate length and placed one shim on each implant. Metal housings are placed on each implant and checked for passive fit over shims (Fig. 8). The head of each implant is shaped like a ball and the retaining fixture acts like a socket. The o-ring snaps over the ball when the denture is seated and holds the denture at a predetermined level of force. Denture is placed in patient's mouth and checked for passive fit over implants and housings. A thin layer of adhesive is applied to the tissue surface of the denture. Pick-up material, i.e. self-curing acrylic is extruded directly onto metal housings and into the troughed denture. The denture is seated in patient's mouth and patient applies normal bite pressure in centric occlusion. Around 7 to 9 minutes are required for material to set. All blockout shims are removed, denture is trimmed and polished (Figs 3 and 9). Final denture is seated and patient is informed to keep the denture in place for the first 48 hours after placement to prevent tissue overgrowth. When seated, the denture gently rests on the patient's ridge. The retaining fixtures allow for vertical movement while withstanding natural lifting forces.

\section{CASE REPORTS}

\section{Case 1}

A 52-year-old male patient reported with favorable edentulous maxilla and unfavorable edentulous mandible.

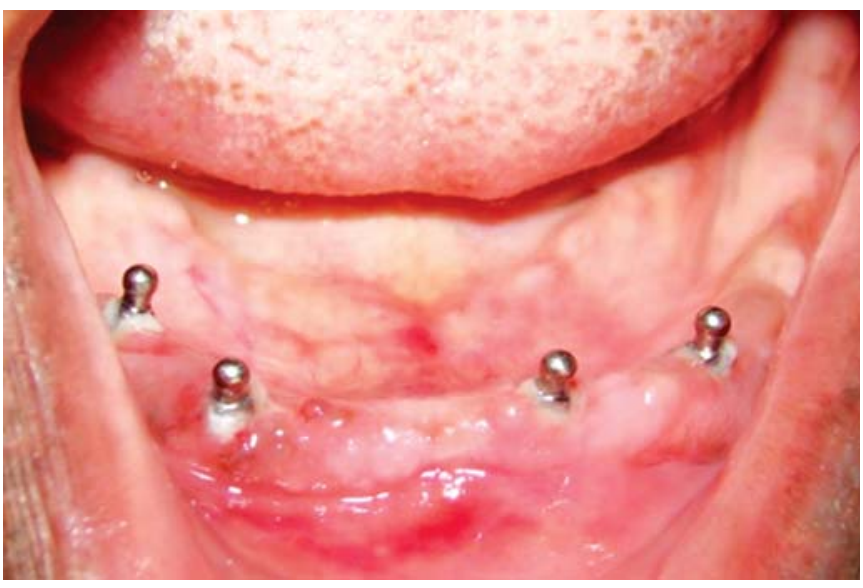

Fig. 2: Implant placed in position

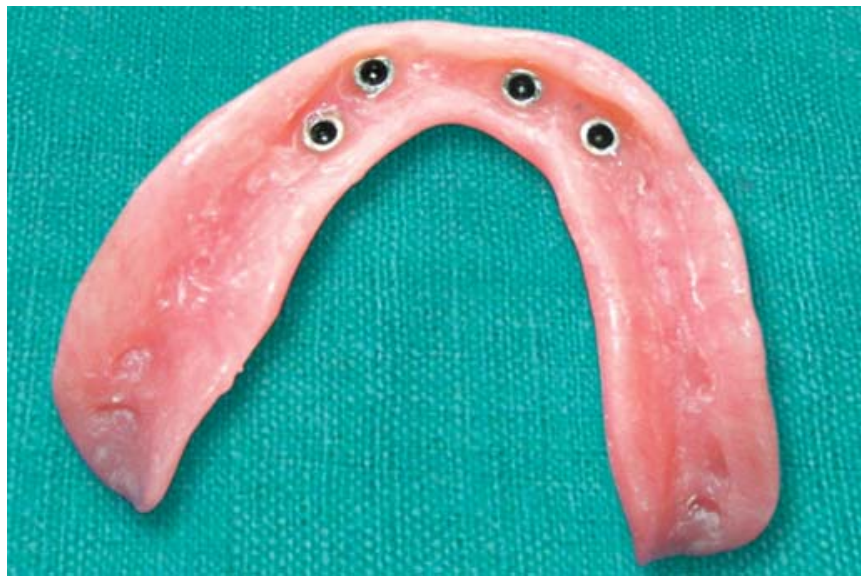

Fig. 3: Metal housings in mandibular denture

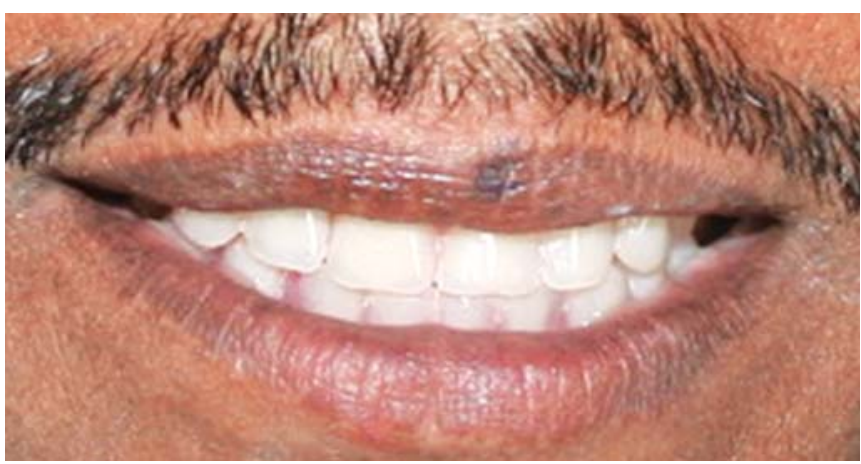

Fig. 4: After insertion 


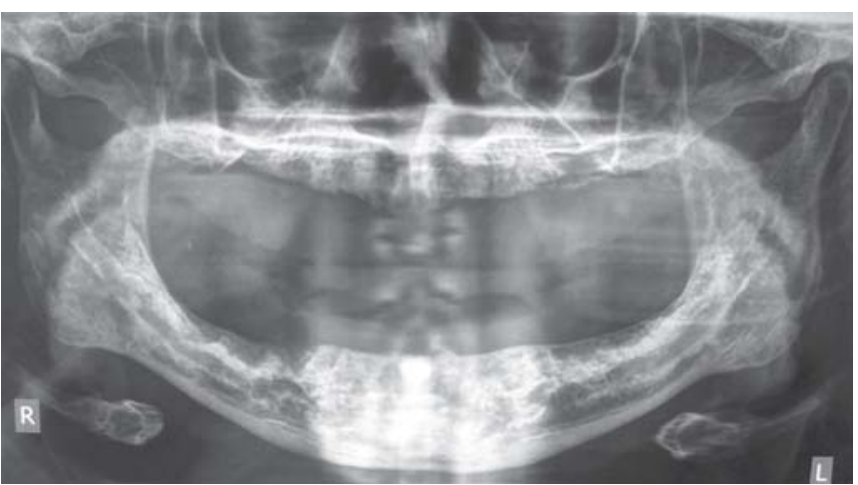

Fig. 5: Preoperative orthopantomogram

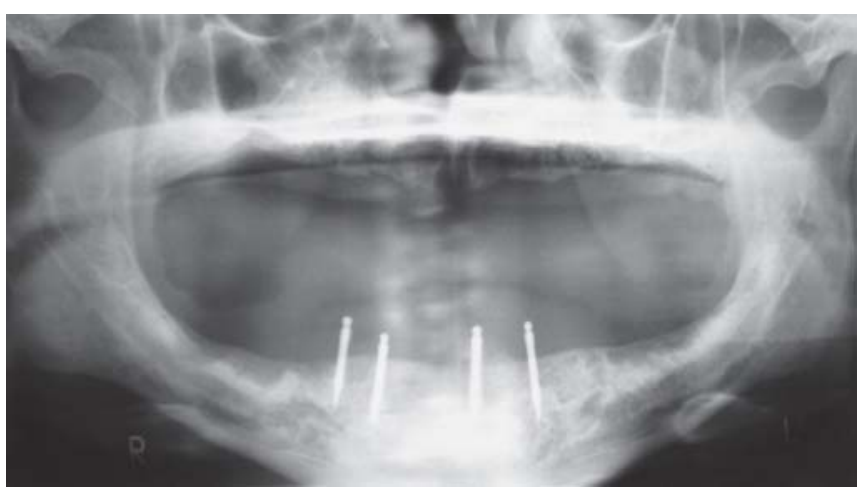

Fig. 6: Postoperative orthopantomogram

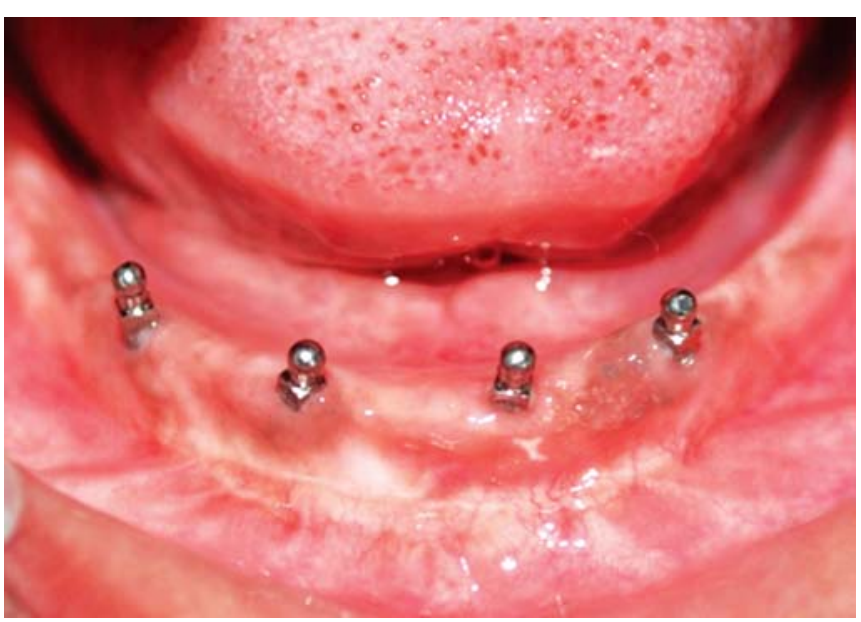

Fig. 7: Implant position in oral cavity

The patient wanted an immediate prosthesis after placement of implants. Maxillary and mandibular dentures were fabricated and delivered before implant surgery. After implant placement, denture was modified and adapted to the ball head of the MDI implants.

\section{Case 2}

A 32-year-old male patient reported with an edentulous mandible and a partially edentulous maxilla. A cast partial denture was fabricated for the maxilla and single complete denture for edentulous mandible. The patient wanted a more retentive mandibular complete denture. After implant

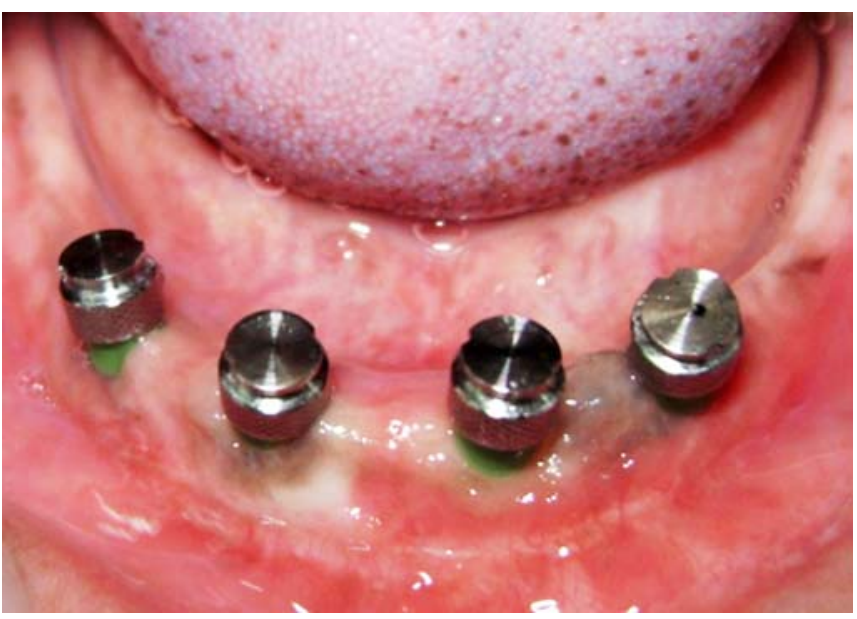

Fig. 8: Metal housings in position

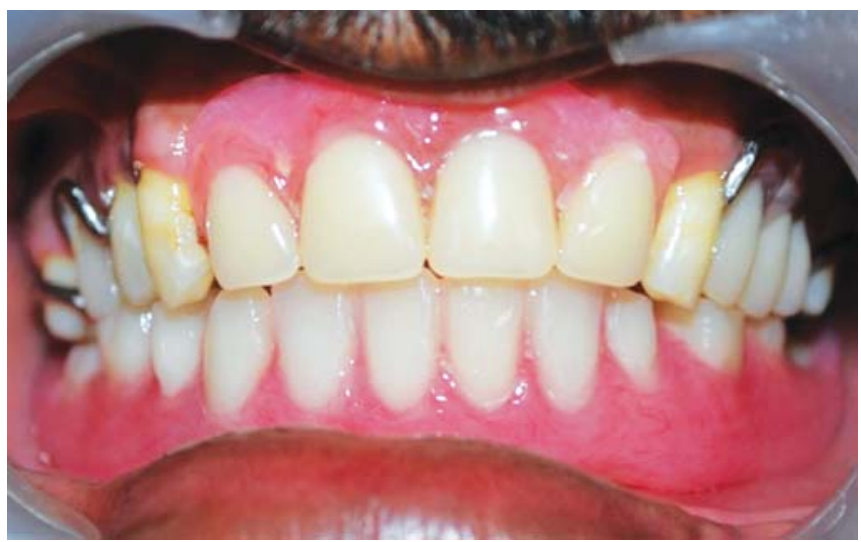

Fig. 9: After insertion

placement, denture was modified and adapted to MDI implants.

\section{CONCLUSION}

Implant-retained overdentures using mini dental implants are a simple and effective treatment alternative to the problem of an unstable mandibular complete denture due to severe ridge resorption. This prosthesis provides immediate mastication and esthetics for patients.

\section{REFERENCES}

1. Glossary of Implant Dentistry.

2. Adell R, Eriksson B, Lekholm U, Branemark P-I, Jemt T. A long-term follow-up study of osseointegrated implants in the treatment of totally edentulous jaws. Int J Oral Maxillofac Implants 1990;5:347-59.

3. Jemt T, Lekholm U. Oral implant treatment in posterior partially edentulous jaws: A 5-year follow-up report. Int J Oral Maxillofac Implants 1993;8:635-40.

4. Allen PF, McMillan AS, Walshaw D. A patient-based assessment of implant stabilized and conventional complete dentures. J Prosthet Dent 2001;85:141-47.

5. Dewan K, Hems E, Owens J. A retrospective study of assess patient satisfaction with implant-stabilized prosthesis. Dent Update 2007;34:470-77. 
6. Complication and maintenance required for fixed prosthesis and overdentures in edentulous mandible: 5-year report. Int J Oral Maxillofac Implants 1994;9:191-96.

7. Christensen GJ. The increased use of small-diameter implants. J Am Dent Assoc 2009;140(6):709-12.

8. Christensen GJ. The 'mini'-implant has arrived. J Am Dent Assoc 2006;137(3):387-90.

9. Himmlova L, Dostalova T, Kacovsky A, Konvicckova S. Influence of implant length and diameter on stress distribution: A finite element analysis. J Prosthet Dent 2004; 91:20-25.
10. Morneburg TR, Proschel PA. Success rate of microimplants in edentulous patient with residual ridge resorption. Int J Oral Maxillofac Implants 2008;23(2):270-76.

11. Campelo LD, Dominguez Camara JR. Flapless Implant Surgery: A 10-year clinical retrospective analysis. Int J Oral Maxillofac Implants 2002;17:271-76

12. Ahn MR, An KM, Choi JH, Sohn DS. Immediate loading with mini dental implants in the fully edentulous mandible. Implant Dent 2004;13(4):367-72.

13. Christensen GJ. Treatment of the edentulous mandible. J Am Dent Assoc 2001;132(2):231-33. 